\title{
Urea Permeability of Citric Acid Crosslinked Chitosan-Poly (Vinyl Alcohol) Blend Membranes
}

\author{
Lusiana R. A., Isdadiyanto S., Khabibi, Siswanta D., and Mudasir
}

\begin{abstract}
Chitosan-citric acid cross-linking reaction showed that group modification group was able to increase the number of carrier compound active groups which led to the increase of membrane transport capacity. Substitution of the carboxyl group was also shown to reduce the adsorption of proteins on the membrane surface. This was confirmed by SEM analysis of the surface both chitosan and CS.cl.CA after contact with albumin. CS.cl.CA membrane transport capacities for urea IS $287 \mathrm{mg} / \mathrm{L}$, respectively. Vitamin $B_{12}$ and albumin were not able to pass through the membrane as indicated by the absence of UV-Vis absorption of both compounds in the acceptor phase. The characterization using FTIR spectrometry showed that cross-linking reaction has occurred for chitosan.
\end{abstract}

Index Terms-Crosslinking, active groups, transport, membrane, adsorption.

\section{INTRODUCTION}

Urea is one of waste substance from the nitrogenated metabolism. Under stable metabolic homeostasis, it is continuously released into human blood. It is excreased via the kidney [1]. Urea and creatinine levels in the blood is a sign of the inability of the kidneys to function disposal. In patients with renal failure, the functions performed by the disposal of hemodialysis equipment [2]. The main element in the artificial kidney machine is semi-permeable membrane with high capacity.

Currently, high performance membranes with variable surface carrier of concern research due to its applications in medical as a biocompatible materials [3]. It looks the main work in obtaining new filtration membranes is concentrated on thin film composite membranes. The work is primarily directed to new polymer with better chemical stability, which allows them to be used as a basic material for the membrane preparation [4].

Chitosan is one of alternative biopolymers that had been used as thin film materials, due to its excellent properties, non-toxicity, biodegradability and biocompatibility. Chitosan membranes have been used as dialyzer for hemodialysis [5]-[7]. These materials has the ability to form thin film membranes but poor binding capacity with target molecule, likes urea and creatinine [11]. In acidic condition, the amine groups can easily be protonated and become positively charged. The positively charged will cause the disturbance of

Manuscript received May 6, 2015; revised July 8, 2015.

Lusiana R. A. and Isdadiyanto S. are with the Department of Chemistry, University of Diponegoro Jl. Prof. Soedarto, Tembalang Semarang, Indonesia (e-mail: lusianaretno@yahoo.com, isdadiyanto@yahoo.com).

Khabibi, Siswanta D., and Mudasir are with the Department of Chemistry, University of Gadjah Mada Jl. Sekip Utara, Yogyakarta, Indonesia (e-mail: khabibi@undip.ac.id). plasma proteins circulation, which turn cause protein adsorption on the surface of the membranes. Significant interest has grown in the modification of chitosan to impart new and improved properties. There are several routes can be used to change the surface of chitosan, the key purpose of which is to alter the chemical composition and the surface properties of chitosan to suit specific application [8], [9].

Citric acid is a weak organic acid that widely used as anticoagulant. Citric acid is a small molecule and cannot be used to be a film membrane direcly [10]. However, the reactive carboxyl groups of citric acid is expected to increase the active sites on the surface of chitosan [11].

Our research is aimed to improve the transport ability of chitosan, using crosslinking reaction of citric acid with chitosan. The $\mathrm{NH}_{2}$ and $\mathrm{OH}$-group located along the open chain of chitosan made this material easy to modify by substituting the hydroxyl group with other groups according to particular purposes [7] in this case for hemodialysis membranes. The crosslinking reaction of chitosan with citric acid is done in order to incorporate the reactive $-\mathrm{COOH}$ groups of citric acid to the backbone chain of chitosan. The substitution is expected to increase the active sites on the surface of chitosan membrane, through urea can be transported via hydrogen bonds formation.

Next, to improve the mechanical properties as well decrease the hydrophilicity of chitosan crosslinked with citric acid, the composite was mixed with the PVA (poly-vynil alcohol) [11]. The appropriate ratio of the hydrophilic groups and the hydrophobic groups is expected help produce a membrane with high mechanical strength and flexibility. In this study, the relationship between the hydrophilicity of the membrane with the ability to transport urea was also studied. PVA is a hydrophilic, elastic, non-toxic and degradable synthetic polymer and has good physical and chemical properties and film-forming ability. The appropriate ratio of the hydrophilic groups and the hydrophobic groups is expected help produce a membrane with high mechanical strength and flexibility.

\section{EXPERIMENTAL}

\section{A. Materials}

Chitosan with deacetylation $>85 \%$ was obtained from Seafresh Chitosan Co, Cirebon (Indonesia). PVA (weight-average molecular weight $=72,000 \mathrm{~g} / \mathrm{mol}$ ) provided by Aldrich Chemical Co. (St. Louis,MO) as the membrane matrix. Chloroacetic acid, sodium hydroxide $(\mathrm{NaOH})$, acetic acid $\left(\mathrm{CH}_{3} \mathrm{COOH}\right)$, hydrochloric acid, ethanol provided by Merck Co. Urea, creatinine was purchased from Sigma Chemical Co (USA). 


\section{B. Preparation and Characterization of Citric acid Crosslinked Chitosan (CS.cl.CA)}

CS.cl.CA was prepared by first dissolving $0.500 \mathrm{~g}$ of chitosan powder $(\mathrm{g})$ in $20 \mathrm{~mL}$ acetic acid solution. After that, amounts of citric acid were added with constant stirring for 4 $\mathrm{h}$ at $80{ }^{\circ} \mathrm{C}$ to reach the desired mole ratio. While stirring, 2 $\mathrm{mL}$ of hydrochloric acid solution was also added. The resulted materials were then analyzed using FTIR for functional groups analysis.

\section{Preparation and Characterization of Blend Membrane}

Poly (vinyl alcohol) PVA was used to prepare CS.cl.CA/PVA blends. Aqueous PVA solutions $(1,5 \% \mathrm{w} / \mathrm{w})$ were mixed with CS.cl.CA $(1,5 \%)$ solutions in different proportions to obtain a series of blends. The thickness of the blend membranes were measured using micrometer.

\section{Swelling Measurements}

Dried membranes with different compositions were weighed, then soaked in phosphate buffer for 6 hours. The membranes were taken out and weighed. The membrane swelling percentage was calculated using the following formula:

$$
\text { Swelling }(\%)=\frac{\left(W_{w}-W_{d}\right)}{W_{d}}
$$

where $w_{w}$ and $w_{d}$ are the weight of hydrated and dried membranes, respectively.

\section{E. Determination of the Thickness}

The film thickness was measured using a micrometer (Mitutoya, Japan) at 5 different positions of the film.

\section{F. Mechanical Properties Measurement}

The mechanical properties of film samples were determinated in dry states. Tensile strength and percentages elongation at break $(\%)$ were measured with a mechanical tensile strength tester.

\section{G. Permeability Test for the Membranes}

Transport process experiments were done by using the following metabolites: urea $500 \mathrm{ppm}$, creatinine $15 \mathrm{ppm}$, and vitamin $\mathrm{B}_{12} 20 \mathrm{ppm}$ in $50 \mathrm{~mL}$ dissolved phosphate buffer solution in the source phase and $50 \mathrm{~mL}$ phosphate buffer only in the acceptor phase. Each compartment is equipped with magnetic stirrer. Solute permeability in passing through the membrane was determined by analysing the concentrations of each solute in the acceptor phase with a UV-Vis spectrophotometer at $0-6$ hours intervals.

\section{RESULTS AND DISCUSSION}

\section{A. Synthesis and Characterization Membrane}

The FTIR spectra can be seen in Fig. 1. CS spectra showed a broad band at $3400 \mathrm{~cm}^{-1}$, indicating the presence of $\mathrm{O}-\mathrm{H}$ groups, while an absorption band at $1635 \mathrm{~cm}^{-1}$ can be attributed to the vibration of primary $\mathrm{N}-\mathrm{H}$ in the amine groups. Citric acid spectra showed a wide absorption band in the region 2900 to $3400 \mathrm{~cm}^{-1}$, which can be attributed to stretching vibration of $\mathrm{O}-\mathrm{H}$ from of the carboxylic group. The band ranged from 1689 to $1759 \mathrm{~cm}^{-1}$ is typical absorption band of carbonyl $(\mathrm{C}=\mathrm{O})$ of carboxylic group. The spectra of CS.cl.CA showed a broader band at $3400 \mathrm{~cm}^{-1}$. The higher intensity of this band might be attributed to the presence of $\mathrm{O}-\mathrm{H}$, both from the carboxylic group of citric acid, and -OH groups of CS. The specific absorption at 1680-1750 $\mathrm{cm}^{-1}$ might be ascribed to $\mathrm{C}=\mathrm{O}$ ester groups, indicating the crosslinking between citric acid and CS chains.

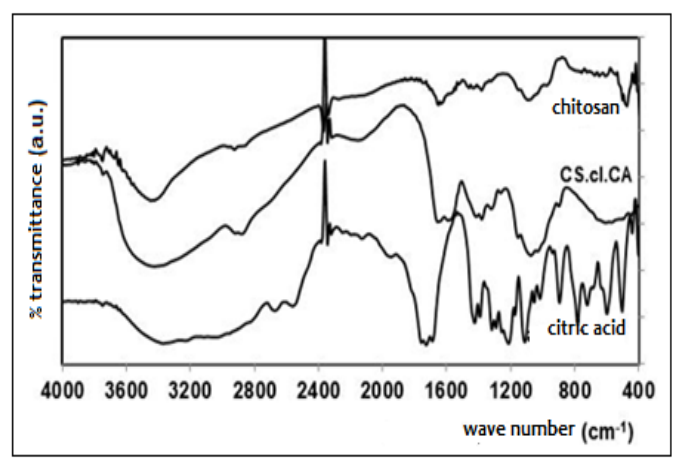

Fig. 1. FTIR Spektra of CS and CS.cl.CA.

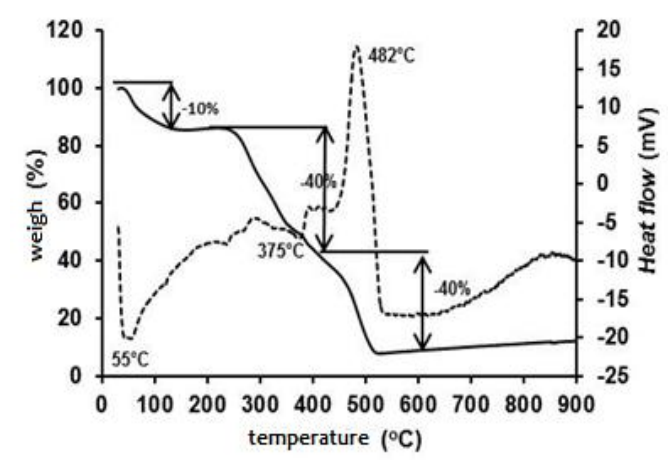

Fig. 2. TG/DTG curves of the CS.cl.CA membranes.

\section{B. TG/DTG Analysis of the Membrane}

Thermograms from TGA and DTG analysis of CS.cl.CA are shown in Fig. 2. Thermogravimetry was conducted at temperatures between $30-900{ }^{\circ} \mathrm{C}$ at a heating rate of $10{ }^{\circ} \mathrm{C}$ min-1. As can be seen in Fig. 3(A), there is a slight weight loss (approximately 5\%) between $30-100{ }^{\circ} \mathrm{C}$, which can be associated to the evaporation of water due to hygroscopic hydroxyl groups. The second decline occurred at temperatures between 200-350 ${ }^{\circ} \mathrm{C}$, associated with heat-related depolimerization molecules. The lossed weight at the temperature was $40 \%$. The third weight loss occurred between $350-525{ }^{\circ} \mathrm{C}$, which can also be attributed to heat-related decomposition of the monomer.

\section{Swelling Behavior of Membrane}

As shown in the Fig. 3 water uptake of samples were increase by crosslinking and blending. Water uptake is attributed to the increasing of hydrophilic groups $(-\mathrm{OH})$ in samples. This is amount of water content, which imparts several unique physiochemical properties of the material. Water absorption test conducted to predict the size of a substance that can diffuse through the membrane material. The water absorption of composite blend CS.cl.CA/PVA has 2-4 times higher than pure chitosan membrane. It is indicated that the more citric acid which can be cross-linked to chitosan made the membranes more hydrophilic. The existence of citric acid as a cross- linker agent is able to increase the 
percentage of water absorption of chitosan due to the increased ability of the interaction between the polymer with water molecules. In the other hand, the blending of PVA with $\mathrm{CS}$ tend to increase the water uptake. The increased swellability of the blends is illustrated in Fig. 3. It is seen the different water uptake in different thicknesses of crosslinked membranes. The most thicknesses of crosslinked membranes have highest of water uptake. Polymer blending is one of the useful ways to have new material with required properties.

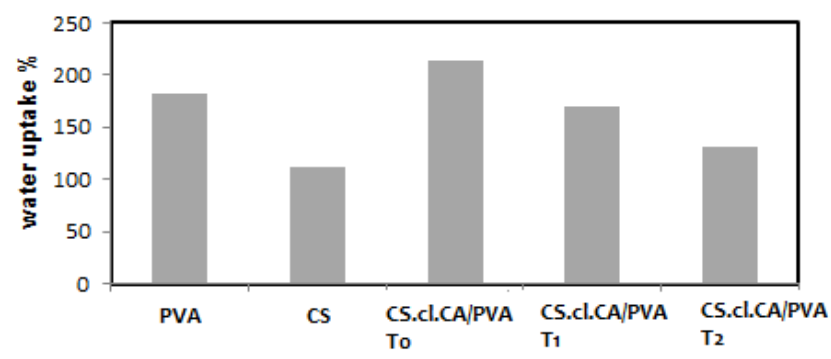

Fig. 3. Variation of water uptake in various membranes.

\section{Mechanical Testing}

The tensile strength at break of the blend membrane as well as pure chitosan and crosslinked chitosan in dry state are given in Table I. Membrane tensile strength measurements indicate the strength and elasticity of the membrane. From the results, it can be observed that the crosslinked blend membrane exhibits higher tensile strength than the CS and CS.cl.CA. This enhancement may be attributed to the ionic-crosslinking of the polymer membranes. This crosslinked reaction causes the chitosan structure becomes more regular and flexible bonds are formed between monomers to one another, causing the membrane elasticity increases. The crosslinked chitosan exhibited better stability compared to CS. The blends also exhibited good stability as their mechanical properties were maintained. Blending improved tensile strength of CS.cl.CA/PVA blend significant. Blending leads to an intermolecul interaction between two polymers and this improves mechanical strength of the blends, the flexilibily of the film were increased.

\section{E. Effect of Membrane Thickness}

Urea transport using membrane with different thickness (Table II) was performed for 6 hours transport time. Membrane thickness indicate weight amount of constituen The results of urea transport on three membranes with different thickness is shown Fig. 4. It can be seen from the figure that the longer transport time, the higher the urea transport percentage. This is due to increasing contact time between the membrane with urea solution. The highest transport capacity was obtained for membrane $\mathrm{T}_{0}$, having transport percentage of $60,4 \%$. Fig. 4 also shows that not only T0 has the highest transport percentage for urea, the membrane also exhibited the highest swelling percentage compared to the other membranes, as can be seen in Table II. Higher permeability was observed for the blended membranes with the most thickness.

TABLE I: TENSILE STRENGTH AND \% ElOngATION OF THE POLYMER

\begin{tabular}{llll}
\hline Polymer & Tensile strength (MPa) & $\begin{array}{l}\text { Elongation at break } \\
(\%)\end{array}$ & \\
\hline Chitosan & 21.62 & 9.24 & \\
CS.cl.CA & 24.50 & 119 & \\
CS.cl.CA/PVA & 29.76 & 151.91 & \\
\hline
\end{tabular}

\section{F. Urea Transport}

TABLE II: Swelling Percentage For CS.CL.CA/PVA Membrane WITH DIFFERENT THICKNESS

\begin{tabular}{cccc}
\hline Membran type & Thickness $(\mu \mathrm{m})$ & \% Swelling & $\begin{array}{c}\text { \% urea } \\
\text { permeated }\end{array}$ \\
\hline T0 & 50 & 220 & 60 \\
T1 & 100 & 175 & 55 \\
T2 & 180 & 140 & 51 \\
\hline
\end{tabular}

\section{THE EFFECTS OF VIT B $B_{12}$ ON THE TRANSPORT OF UREA}

The effects of vitamin $B_{12}$ on urea transport were studied by combining the three species in the source phase. The transport of the three species mixture was done for 6 hours using a membrane $\mathrm{T}_{50}$, and the results can be seen in Fig. 5 .

Vitamin $B_{12}$ is one of the molecules present in blood together with creatinine and urea. Having a molecular weight of $1355 \mathrm{~g} / \mathrm{mol}$, the molecular size of vitamin $\mathrm{B}_{12}$ is so large that it hinders the transport processes of creatinine and urea. The transport percentages of urea transport for the three species mixture are lower than when urea were transported individually. The transport percentage of urea decreased from $60.36 \%$ to $53 \%$. The large molecular size of vitamin $\mathrm{B}_{12}$ seems to have a significant influence on the transport percentage of the other metabolites.

Additionally, the presence of vitamin $\mathrm{B}_{12}$ in the source phase also reduces the percentage of urea transport. With very large molecular size, vitamin $\mathrm{B}_{12}$ might hinder urea to enter the membrane pores. The competition of the three metabolites to approach the membrane surface may also cause additional collision between the molecules, so that it is difficult for urea to enter the membrane pores which lead to so longer transport time. The presence of vitamin $B_{12}$ that covers the pores might also be one of the reasons for the decline in the transport percentage for urea, as the molecules were able to block urea from passing through the membranes.

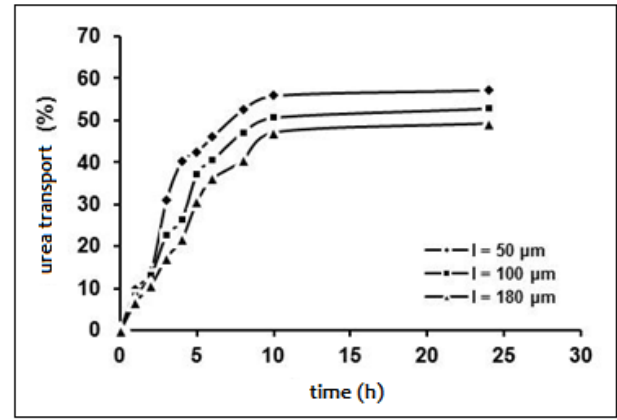

Fig. 4. Percentage of urea transport of membrane CS.cl.CA/PVA in various membrane thickness.

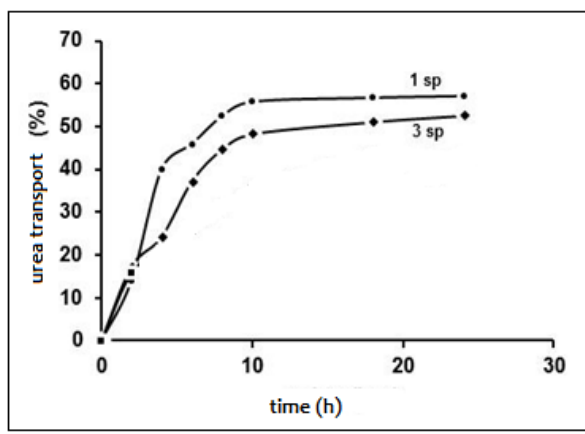

Fig. 5. Urea transport of membrane in different substituent in the solution (1 $\mathrm{sp}=$ urea, $3 \mathrm{sp}$ : urea, creatinine \& vit $\mathrm{B}_{12}, 4 \mathrm{sp}:$ urea, creatinine, albumin \& vit $\left.\mathrm{B}_{12}\right)$. 


\section{CONCLUSION}

Sufficient membrane material is biocompatible and has mechanical strength has to be synthesized from chitosan derivatives substituted carboxyl groups on the amine group. Sufficiently high membrane permeability to urea. There is a relationship between the increase in water uptake by the increase of membrane transport capabilities. Thinner membranes seem to have a higher water uptake compared with a thicker membrane. This turned out to be in line with the ability of membrane transport. The thin membrane with the highest uptake of water has the highest transport capability.

\section{ACKNOWLEDGMENT}

Thanks a lot to the director general of higher education, ministry of education and culture, indonesia.

\section{REFERENCES}

[1] B. Khadro, C. Sanglar, A. Bonhomme, A. Errachid, and N. Jaffrezic-Renault, "Moleculary inprinted polymer (MIP) based electrochemical sensor for detection of urea and creatinine," Procedia Eng., 2010, vol. 5, pp. 371-374.

[2] M.-H. Lee, T.-C. Tsai, J. L. Thomas, and H.-Y. Lin, "Recognition of creatinine by poly(ethylene-co-vinylalcohol) molecular imprinting membrane," Desalination, 2008, vol. 234, pp. 126-133.

[3] A. S. Aly, H. A. Salah, A. S. Fahmy, and S. A. Mohamed, "Preparation of high performance membrane for biomolecules separation," Aust. J. Basic Appl. Sci., 2010, vol. 4, no. 6, pp. 1137-1145.
[4] R. A. Lusiana, D. Siswanta, and Mudasir, "Permeability of Urea in N-carboxymethyl chitosan/poly(vinylalcohol) blend membranes for hemodialysis," presented at International Conference Chemistry and Apllication, Hong Kong, July 6-7, 2013.

[5] E. Lacson, Jr. and S. M. Barnelli, "Hemodialysis treatment time: a fresh perpective," Clin. J Am Soc Neprol, vol. 6, pp. 2523-2530, 2011.

[6] M. M. Amiji, "Permeability and blood compatibility properties od chitosan-poly(ethylene oxide) blend membranes for haemodialysis," Biomater, vol. 16, pp. 593-599, 1995.

[7] V. Balan and L. Verestiuc, "Strategies to improve hemocompatibility: A review," Eur. Polym. J., vol. 53, pp. 171-183, 2014.

[8] V. P. Hoven, V. Tangpasuthadol, Y. Angkitpaiboon, N. Vallap, and S. Kiatkanjornwong, "Surface-charged shitosan: Preparation and protein adsorption," Carbohydr. Polym, vol. 68, pp. 44-53, 2007.

[9] M. N. V. R. Kumar, "A Review of chitin anf chitosan applications," React. Funct. Polym, vol. 46, pp. 1-27, 2000.

[10] L. Li, C. Cheng, T. Xiang, M. Tang, W. Zhao, S. Sun, and C. Zhao, "Modification of polyethersulfone hemodialysis membranr by blending citric acid grafted polyurrthane and its anticoagulant activity,' J. Memb, Sci., pp. 405-405, 261-274, 2012.

[11] R. A. Lusiana, D. Siswanta, Mudasir, T. Hayashita, "The Influence of citric acid crosslinked PVA/chitosan membrane hydrophilicity on the transport of creatinine and urea," Indo J. Chem, vol. 13, no. 3, pp. 262-270, 2013.

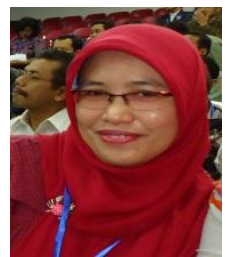

R. A. Lusiana was born in Grobogan, Central Java (Indonesia) on December 2, 1970. She received her doctor's degree in analytical chemistry from the Universitas Gadjah Mada, Indonesia in 2014. At present, she is a lecturer in the Department of Chemistry Universitas Diponegoro Semarang, Indonesia. Her area of interest is about membrane form biomaterials. 